\title{
Early agriculture at the crossroads of China and Southeast Asia: Archaeobotanical evidence and radiocarbon dates from Baiyangcun, Yunnan
}

Rita Dal Martello, Rui Min, Chris Stevens, Charles Higham, Thomas Higham, Ling Qin, Dorian Q Fuller

\begin{abstract}
We report archaeobotanical results from systematic flotation at what is presently the earliest Neolithic site with hard evidence for crop cultivation in the Southwestern Chinese province of Yunnan, at the site of Baiyangcun. Direct AMS dates on rice and millet seeds, included together in a Bayesian model, suggests that sedentary agricultural occupation began ca. $2650 \mathrm{BCE}$, with cultivation of already domesticated rice (Oryza sativa), broomcorn millet (Panicum miliaceum), and foxtail millet (Setaria italica). Soybean (Glycine cf. max) was also present and presumably cultivated, although it still resembles its wild progenitor in terms of seed size. Additional possible cultivars include melon (Cucumis melo) and an unknown Vigna pulse, while wild gathered resources include fruits and nuts, including hawthorn (Crateagus) and aquatic foxnut (Euryale ferox). Weed flora suggests at least some rice was cultivated in wet (flooded or irrigated fields), while dryland weeds may derive from millet fields. This subsistence system persisted throughout the site's occupation, up to ca. $2050 \mathrm{BCE}$. These data provide secure evidence for the spread of Chinese Neolithic crops to Yunnan, and provide new evidence for reconstructing possible sources of cereal agriculture in mainland Southeast Asia.
\end{abstract}

\section{Introduction}

In many regions the Neolithic transition resulted from the migration of farmers and the spread of key cereal crops from their centres of domestication. In mainland Southeast Asia, evidence has long pointed to the introduction of rice agriculture in the Neolithic via dispersal processes from the Yangtze Valley region of China (e.g. Higham, 1996; Bellwood and Renfrew, 2002; Castillo and Fuller, 2010; Silva et al., 2015; Castillo et al., 2016a, Castillo et al., 2016b). In recent years, it has become evident that Neolithic cultivation in Southeast Asia also included foxtail millet (Setaria italica), another Chinese domesticate but derived from the more northern loess-based Neolithic traditions (Weber et al., 2010; Castillo and Fuller, 2010; Liu et al., 2009; Qin, 2012; Stevens and Fuller, 2017). The route or routes by which migrating farmers and/or their crops moved from China to Southeast Asia has been open to discussion, with at 
least three major axes under consideration: (1) a coastal route that started in Taiwan and Fujian (e.g. Bellwood, 1991, Bellwood, 1995; Sagart, 2005; Bellwood and Dizon, 2008); (2) a route from the middle Yangtze to the Lingnan and the Pearl river basin in Guangdong and then onwards through Guangxi into Vietnam (e.g. Fuller et al., 2011); (3) up the Yangtze to Yunnan and then moving down various north-south rivers, such as the Mekong, into Southeast Asia (Higham, 1996, Higham, 2002a). Potentially two, or all three, of these routes could have been followed in parallel, and various language phyla in Southeast Asia (e.g. Austronesian, AustroThai, Austroasiatic, Tibeto-Burman) do suggest multiple southward and westward dispersals of farmers in prehistory (see, e.g. Higham, 2002b; Blench, 2005; Bellwood, 2005; Van Driem, 2005; Stevens and Fuller, 2017). The degree to which the present archaeobotanical data can support any of these routes is highly variable. Any or all of these scenarios fits with straightforward processes of spatial diffusion of rice from one or two centres of domestication in the Middle and Lower Yangtze (Silva et al., 2015), however the southern routes fit less well with the dispersal of millet. Nevertheless, archaeobotanical sampling from the southern provinces of China has been quite limited, and the present paper reports results from new efforts at systematic flotation for archaeobotanical remains in Yunnan province coupled with direct AMS-radiocarbon dating of crop remains. Given the late date of rice within southern China, e.g. after 2500 BCE (e.g. Zhang and Hung, 2008; Yao, 2010; Zhang and Hung, 2010; Yang et al., 2017), the dating of early sites in Yunnan and the nature and crop composition are key to understanding this agricultural transition and the migration of farming communities into Southwest China and beyond.

With respect to these possible routes, we report the first flotation results from the Neolithic site of Baiyangcun in north-western Yunnan province China (see Fig. 1). Based on excavation over 35 years ago and the chance recovery of rice (Yunnan Provincial Museum, 1981), this site has played an important role in inferring the presence of rice cultivation by ca. $2300 \mathrm{BCE}$ in this region as a possible precursor to the spread of rice to mainland Southeast Asia (e.g. Higham, 2002a). Some questioned whether or not these finds were intrusive (e.g. D'Alpoim Guedes and Butler, 2014), but new sampling and direct dating reported here suggest otherwise. New excavations were carried out at the site in 2013-2014 by the Yunnan Province Institute of Archaeology, including systematic archaeobotanical sampling through flotation, with subsequent laboratory analyses ongoing through collaboration between Peking University and UCL, with selected grains directly dated by AMS radiocarbon in Oxford, and Glasgow respectively.

\subsection{Baiyangcun site and excavations}

The site of Baiyangcun (白羊村) is located in the Dali Bai Autonomous Prefecture (大理白族 自治州) in Binchuan county (宾川县), north-western Yunnan (Fig. 1). Binchuan county is 
surrounded by high mountains, reaching a maximum altitude of 3700 masl in the northwest, and a lowest elevation of about 1000 masl in the southeast (see Fig. 1). The area is within the influence of the subtropical monsoon, and characterized by distinctive wet and dry seasons, with an annual average temperature of $12-15^{\circ} \mathrm{C}$, and annual average rainfall of about $750 \mathrm{~mm}$ ( $\mathrm{Li}$ and Walker, 1986). The Baiyangcun site is located in the middle Jinsha (金沙江) Valley on the banks of the Bingju tributary River, about $3 \mathrm{~km}$ east of Binchuan.

Discovered in 1972, the site underwent one excavation campaign from November 1973 to January 1974. On this occasion, a total area of $290 \mathrm{~m}^{2}$ was excavated and 8 cultural layers were identified that reached a depth of $4.35 \mathrm{~m}$ (Yunnan Provincial Museum, 1981). Excavated features included 11 house foundations, 14 fire places, 48 ash and storage pits, and 34 graves. Postholes were found along the perimeter of all house foundations, which were most likely constructed as wattle and daub structures. Storage pits were located around the buildings, and were distinguished by their shape as rounded, oval, rectangular and irregular opening features. Extended inhumation burials in rectangular graves dominated numerically, and a few urn burials were also found. Common burial customs included the placing of the dead in extended supine position, and the removal of the skull (a phenomenon found in about a third of the graves). A few secondary and multiple burials were also found. All deposits were associated with Neolithic cultural remains, which were found in and around the features in the form of ceramic sherds, stone, bone, and shell tools (for a more detailed description of the material culture excavated in this occasion see Rispoli, 2007; Chang, 1964). According to the original excavation report, findings of "white ashes", interpreted as siliceous rice glumes, were discovered in several storage pits, as well as numerous pig, cattle, and sheep/goat bones. Radiocarbon dates were taken on charred wood remains from posthole number 2 of house F3, and from an unnumbered posthole from trench 7, implied occupation of the site to be between 2464 and 1974 cal. B.C. (ZK-0220, $3770 \pm 85$ BP)/2336-1777 cal. B.C. (ZK-0330, $3675 \pm 85$ BP) (Yunnan Provincial Museum, 1981; Zhang and Hung, 2010; CASS, 1978; see Table 2). Two main cultural periods were identified within these early excavations: an earlier encompassing layers (8) to (6), and a later period, comprising layers (5) to layer (2). No previous occupation seemed to have taken place, as early house structures cut straight into the bedrock (F7-F11), while later structures (F1-F6) were constructed on top of the early abandoned remains. Rounded storage pits were found to be exclusively associated with the later period.

Although rice remains were found during the first excavation of Baiyangcun, a number of problems persisted with the original methods of recovery, as no flotation was carried out, and the cultivation of rice was assumed rather than demonstrated through systematic analysis of macro botanical remains (D'Alpoim Guedes and Butler, 2014). The overall area of the site was estimated at $3000 \mathrm{~m}^{2}$, however due to the continuous erosion activity caused by the action of 
the nearby river and modern agriculture, the true size of the site and the overall depositional process still remained very unclear.

In order to clarify these issues, the Yunnan Province Institute of Cultural Relics and Archaeology launched a new campaign of excavations at Baiyangcun in 2013-2014. The new excavation area was set on the northwest limit of the first excavation area. A total of $100 \mathrm{~m}^{2}$ divided between two trenches of $5 \times 10 \mathrm{~m}^{2}$ was dug. Trench 1 covered the northern side of the new excavation area, and 23 cultural layers were identified, reaching a depth of $4.8 \mathrm{~m}$. Trench 2 covered the southern side of the new excavation area, and 24 cultural layers were revealed, also reaching an overall depth of $4.8 \mathrm{~m}$. Although more detailed, the layers' division of the new excavation corresponds directly with the original 8 layers. Features exposed over the course of the second excavation include 18 house foundations, 11 fire places, 248 ash and storage pits, and 23 graves. This most recent excavation report is still unpublished.

\section{Materials and methods}

Over the course of the 2013-14 excavations, $>300$ samples of between 5 and $20 \mathrm{~L}$ were taken, both from cultural layers and features. Floats were collected using a $0.3 \mathrm{~mm}$ mesh, and each sample was dried naturally and then sieved to obtain $4 \mathrm{~mm}, 2 \mathrm{~mm}, 1 \mathrm{~mm}, 0.5 \mathrm{~mm}, 0.25 \mathrm{~mm}$, $<0.25 \mathrm{~mm}$ fractions. Standard sampling was carried out by the same individuals, and therefore we attribute difference between samples, in terms of item density and taxon representation to archaeological factors, either taphonomy or past human activity. Samples were sorted and all macro botanical remains were extracted from each fraction and identified under a stereo binocular low power microscope at magnifications of up to $\times 40$ through comparisons with charred and modern reference material held at the Institute of Archaeology UCL. They were then recorded following the nomenclature of eFloras' revised Chinese flora ( $\underline{\mathrm{Wu}}$ et al., 2013; www.efloras.org). The present study is based on full analysis of 35 samples chosen to represent the stratigraphic sequence of the site. These include at least one sample from each cultural deposit to form a complete top to bottom stratigraphic sequence, and two additional ash pit deposits that were initially analysed to assess the preservation conditions at the site.

In order to establish the chronology of the site, direct AMS-radiocarbon dating was carried out on rice and millet grains from the sequence of occupation layers within Trench 2 and additionally from feature H118 (sealed by layer 15). Material was selected and AMS dated at the Oxford University Radiocarbon Accelerator Unit (ORAU), and at the Scottish Universities Environmental Research Centre Radiocarbon Laboratory. The stratigraphic ordering of these dates means that it is possible to refine their calibrations through use of Bayesian statistical modelling of the dates as a sequence, which was carried out using the OxCal software (Bronk Ramsey, 2009). This also allowed for boundaries to be modelled that represent the start of the sequence, the end of the sequence and the transition between phases. 


\subsection{Chronometrics results: dates and sequence}

The archaeobotanical samples provided the opportunity to develop a more robust and precise chronology for the site on the basis of high-precision AMS dates on short-lived materials. Direct AMS dates on rice grains have the advantage that the rice itself only acquire radiocarbon in a particular year and could only have reached the site through human actions of harvesting and crop-processing. The radiocarbon determinations are shown in Table 1(see also Supplementary information for the AMS pre-treatment and analytical data).

The recorded excavation sequence allows us to use the stratigraphy as a prior in a Bayesian model (Bronk Ramsey, 2009), and obtain probabilistic age ranges corresponding with the start and end of Period 1 and the subsequent phase consisting of Periods 2 and 3, which are recognized on the basis of ceramics. The INTCAL13 dataset was used in the calibration (Reimer et al., 2013). We used a General Outlier Model in order to explore the potential for outlying results that do not find agreement with the archaeological sequence. These were assigned a probability of 0.05 .

The ceramic data from the site supports the idea of two broad occupation periods; an early period running from the base of the mound, layer 24 to layer 17, and a later period from at least layer 15 to layer 8, including H118. A Bayesian model of two phases is shown in Fig. 2. It suggests that occupation of the site began ca. $2650 \mathrm{BCE}$, and certainly no later than $2500 \mathrm{BCE}$. The first occupation phase lasted between 237 and 406 years (86\% probability). A more detailed stratigraphic sequence model is illustrated in Fig. S1.

The Bayesian model implies that a possible hiatus in occupation (0-221 years) followed (Fig. 2), although this is not a statistically significant interval since the interval overlaps with zero. The second phase of activity continued until 2179-1991 BCE. There were no significant outliers identified within the modelling; all posterior probabilities were less than the prior probability, which suggests a robust and internally consistent chronometric sequence. 
Table 1. Radiocarbon dates from Baiyangcun. Calibrated ranges are given at 68.2 and $95.4 \%$ probabilities using OxCal 4.3 and the INCAL13 curve (see Fig. 2).

\begin{tabular}{|c|c|c|c|c|c|}
\hline \multirow[t]{2}{*}{ Context } & \multirow[t]{2}{*}{ Material } & \multirow{2}{*}{$\begin{array}{l}\text { Lab } \\
\text { Code }\end{array}$} & \multirow{2}{*}{$\begin{array}{l}\text { Cal. date } \\
\text { BP }\end{array}$} & \multirow{2}{*}{$\begin{array}{l}\text { Calibrated age } \\
\text { BCE } \quad(68.2 \% \\
\text { prob.) }\end{array}$} & \multirow{2}{*}{$\begin{array}{l}\text { Calibrated age } \\
\text { BCE } \quad(95.4 \% \\
\text { prob. })\end{array}$} \\
\hline & & & & & \\
\hline $\begin{array}{l}\text { F3 posthole } 2 \text { (1973 } \\
\text { exc.) }\end{array}$ & $\begin{array}{l}\text { Wood } \\
\text { charcoal } \\
\text { (bulk) }\end{array}$ & ZK-0220 & $37660 \pm 85$ & 2190-1920 & 2296-1860 \\
\hline $\begin{array}{l}\text { Unnumbered } \\
\text { posthole from } \\
\text { trench } 7 \text { (1973 exc.) }\end{array}$ & $\begin{array}{l}\text { Wood } \\
\text { charcoal } \\
\text { (bulk) }\end{array}$ & ZK-0330 & $3570 \pm 85$ & 2030-1770 & 2190-1690 \\
\hline \multicolumn{6}{|l|}{2013 excavation: } \\
\hline Layer 8 & Rice grain & $\begin{array}{l}\text { OxA- } \\
33,286\end{array}$ & $3743 \pm 29$ & 2201-2060 & 2276-2036 \\
\hline Layer 8 & Rice grain & $\begin{array}{l}\text { OxA- } \\
33,290\end{array}$ & $3764 \pm 28$ & 2271-2138 & 2287-2050 \\
\hline Layer 9 & Rice grain & $\begin{array}{l}\text { OxA- } \\
33,291\end{array}$ & $3718 \pm 29$ & 2193-2041 & 2201-2031 \\
\hline Layer 9 & Rice grain & $\begin{array}{l}\text { OxA- } \\
33,327\end{array}$ & $3689 \pm 35$ & 2135-2031 & 2197-1966 \\
\hline $\begin{array}{l}\text { H118 (sealed by } \\
\text { layer 15) }\end{array}$ & Rice grain & $\begin{array}{l}\text { OxA- } \\
33,328\end{array}$ & $3731 \pm 30$ & 2198-2046 & 2267-2032 \\
\hline $\begin{array}{l}\text { H118 (sealed by } \\
\text { layer 15) }\end{array}$ & Rice grain & $\begin{array}{l}\text { OxA- } \\
33,293\end{array}$ & $3735 \pm 29$ & 2199-2051 & 2267-2035 \\
\hline Layer 17 & Rice grain & $\begin{array}{l}\text { OxA- } \\
33,287\end{array}$ & $3916 \pm 29$ & 2469-2348 & 2476-2299 \\
\hline Layer 17 & Rice grain & $\begin{array}{l}\text { OxA- } \\
33,292\end{array}$ & $3898 \pm 29$ & $2462-2346$ & 2469-2298 \\
\hline Layer 20 & $\begin{array}{l}\text { Setaria italica } \\
\text { millet grains } \\
(n=3)\end{array}$ & $\begin{array}{l}\text { SUERC- } \\
73806\end{array}$ & $3929 \pm 23$ & 2474-2349 & 2488-2339 \\
\hline Layer 21 & Rice grain & $\begin{array}{l}\text { OxA- } \\
33,288\end{array}$ & $3958 \pm 30$ & 2566-2411 & 2570-2347 \\
\hline Layer 21 & Rice grain & $\begin{array}{l}\text { OxA- } \\
33,289\end{array}$ & $4035 \pm 28$ & 2580-2491 & 2624-2475 \\
\hline Layer 24 & $\begin{array}{l}\text { Setaria italica } \\
\text { millet grains } \\
(\mathrm{n}=3)\end{array}$ & $\begin{array}{l}\text { SUERC- } \\
73802\end{array}$ & $4110 \pm 34$ & 2853-2584 & 2868-2573 \\
\hline
\end{tabular}




\section{Results}

\subsection{General features of the assemblage and key economic taxa}

A preliminary total of 35 samples were sorted and are presented in this paper. Of these, 18 come from Trench 1, and 17 from Trench 2. Apart from two samples taken from rubbish pits (both from Trench 2), all other samples were taken from cultural layers (see Table 2). Average sample volume was about $7 \mathrm{~L}$, seed densities were calculated for Period 1 of $c$. 30 items per litre, and for Periods 2/3 of c. 16 items per litre. This may reflect better preservation in the older and lower layers or else a change in the intensity of plant-based activities that resulted in charred preservation.

Table 2. Summary of flotation samples and plant remains by period and context type.

\begin{tabular}{llll}
\hline & $\begin{array}{l}\text { Period } \\
\text { 2650-2300 cal. } \\
\text { (modelled phase) }\end{array}$ & $\begin{array}{l}\text { 1 } \\
\text { BCE }\end{array}$ & $\begin{array}{l}\text { Periods } \\
\text { 2200-2050 cal. } \\
\text { (modelled phase) }\end{array}$ \\
BCE
\end{tabular}


The majority of the samples appeared rich in charred remains, yielding $>30$ species identified from 5979 plant remains. Identifiable remains were classified into the following categories; cultivated cereal remains, pulses, other edible species (fruits and nuts), and seeds of weed species (grasses, sedges and other weeds). Rice and millet crops occurred throughout the sequence, suggesting that agriculture was central to the economy throughout the occupation of Baiyangcun.

\subsection{Crops}

Cultivated cereals are the most well represented category in the assemblage, representing $>80 \%$ of the total identifiable remains (Table S1). The raw count data shows that rice (Oryza sativa) is the most prevalent species, accounting for almost $50 \%$ of the total identifiable remains. Foxtail millet (Setaria italica) is the second most common species and, together with broomcorn millet (Panicum miliaceum), accounts for around one third of the total identifiable remains. Rice is the most ubiquitous species, present in almost all sorted samples, foxtail millet (Setaria italica) and broomcorn millet (Panicum miliaceum) were present in more than half of the samples (ig. 3). Rice is represented by both grains and spikelet bases (Fig. 4A, D), whereas millets are only represents by grains (Fig. 4B, C).

Recent research has proposed that there were at least two, and perhaps four or five, possible centres for rice domestication in China; two in the Middle and Lower Yangtze Valley regions, and possibly further centres in the Lower Hanshui/Upper and Middle Huai Valley region (Gross and Zhao, 2014; Silva et al., 2015; Deng et al., 2015; Stevens and Fuller, 2017). The earliest finds of rice cultivation have been found at sites from these areas from the 7th millennium BCE onwards. Later finds of rice remains, associated with clear evidence of domestication, assessed through spikelet bases and rice grain morphometrics, have suggested that rice underwent a long and protracted domestication process over at least 2500-3000 years (see Fuller et al., 2009, Fuller et al., 2014 for data from the Lower Yangtze region; Deng et al., 2015 for the Hanshui; and Qin, 2012; Fuller et al., 2016a, for more general overviews). It has been proposed that rice became fully domesticated at around 4000-3700 BCE in the Lower Yangtze Valley, and although clear data from the Middle Yangtze region are still lacking, it has been hypothesized that rice became domesticated there at a roughly similar, or slightly earlier, date (Nasu et al., 2012; Gross and Zhao, 2014). New data from the Hanshui valley suggest that domestic rice cultivation in the region was present by $6300 \mathrm{BCE}$ (Deng et al., 2015), and was well underway in the Lower Huai region during the Shunshanji culture before 6000 BCE (Nanjing Museum, 2016).

Previous studies on early rice have proven how the examination of spikelet bases is useful to assess the domestication status of the crop, especially in terms of its evolving reliance on 
planting by farmers (Fuller et al., 2009; Fuller and Allaby, 2009; Fuller et al., 2014; Deng et al., 2015; Castillo et al., 2016a, Castillo et al., 2016b). Following the criteria outlined in Fuller et al. (2009), rice spikelet bases from Baiyangcun were examined to classify rice remains in more detail. Wild spikelet bases are usually characterized by a smooth, round and symmetrical abscission scar, produced by natural shattering. Having lost the ability to shatter naturally, domesticated rice requires threshing after harvest, which results in an uneven, torn, asymmetrical abscission scar in spikelet bases. Immature grains are harvested alongside fully mature grains particularly when ripening is still asynchronous; their spikelet bases can be distinguished from fully mature ones by the presence of a protruding, broken rachilla still attached to the stem.

Within the samples from this study, a few have high concentrations of spikelet bases (ig. 4D), which could suggest inputs from primary dehusking waste; other samples present a higher grain/grain fragments count, which could indicate cooking waste, or secondary refuse from which spikelet bases have been filtered out by transport and redisposition, i.e. spikelet bases may be reduced either by secondary destruction of loss during sweeping activities. Overall, 179 spikelet bases were found. Domesticated spikelet bases take up about 76\%, immature $11 \%$, and wild spikelet bases just below 4\% (8\% were too broken to be clearly identified). Wild spikelet bases are present in a very low count; thus we can safely infer that rice at Baiyangcun was transmitted to the region as a fully domesticated crop, as might be expected. The presence of wild rice is comparatively low, with between 10\%-20\% wild types recorded in central China Longshan and Yangshao sites (Fuller et al., 2010) and 6\%-12\% recorded at Iron Age sites in India and southern Thailand (Castillo et al., 2016a, Castillo et al., 2016b). The low presence of wild spikelet bases implies that wild rice (O. rufipofon) did not infest these early fields as a weed to any great extent; this is to be expected at higher elevations such as the middle Jinsha Valley, although it could also reflect effective and intensive hand weeding of rice crops.

In Yunnan only a few early sites, dating roughly from 2600 BCE onwards have produced rice remains (Fig. 1): Baiyangcun, Dadunzi, Haidong, Xinguang, Shifodong and Mopandi sites (Yunnan Provincial Museum, 1981; Xiao, 2001; Yunnan Provincial Institute of Cultural Relics and Archaeology, Dali County Cultural Relics and Yongping Cultural Relics, 2002; Yunnan, 2003; Zhao, 2010; Zhang and Hung, 2010; Yao, 2010; D'Alpoim Guedes and Butler, 2014; Jin et al., 2014; Li et al., 2016). However, only at Baiyangcun, Dadunzi and Shifodong have rice remains been recovered through systematic flotation. Given the late rise of agriculture in this area, scholars have hypothesized that it was transmitted to Yunnan from the Yangtze Valley, although which route was followed is still under discussion (Zhang and Hung, 2010; Yao, 2010). Many of these previous studies have focused on the spread of language families (e.g. Higham, 2002b; Bellwood, 2005; Van Driem, 2005) and only recently has there been an 
increasing interest in finding archaeological hard evidence to investigate these claims, as exemplified by this research. Recently, Jin et al. (2014) reported results from the Dadunzi Neolithic site in northern Yunnan based on results obtained from systematic flotation. The archaebotanical assemblage at Dadunzi is dominated by millet grains, with rice occupying only $5 \%$ of the total seed assemblage (Jin et al., 2014). However, many spikelet bases were recovered (3520), which were not included in the $5 \%$, so the importance of rice is likely underestimated. Evidence of phytoliths from the 1st millennium BCE at additional sites in the region, indicate that rice cultivation was widespread by this period (Liu et al., 2016; Li et al., 2016), although it could be contended that the limited application of systematic flotation means that the phytolith record is biased towards rice, which is more readily recognized from single cell leaf or spikelet morphotypes than millets (see Harvey and Fuller, 2005; Weisskopf and Lee, $\underline{2016)}$.

Millet identifications were made in line with categories and criteria outlined by Deng et al. (2015) with immature grains separated following Song et al. (2012). Immature grains of both Setaria and Panicum were recovered from Baiyangcun; immature grains resemble general characteristics of fully mature ones, but are usually flatter and smaller. Distinguishing between Setaria and Echinochloa has sometimes proven difficult, and Echinochloawas systematically differentiated from Setaria through the close examination of the embryo, which reaches a maximum breadth at the lower end in Echinochloa (the maximum breadth in Setaria is the centre of the embryo), and the presence of a hilum that is broader than it is long. Remains of possible Setaria cooking by-products have been recovered from one sample, and they are awaiting further assessment through SEM analysis.

The domestication of millets in China is still poorly understood. Whereas the wild ancestor of Setaria italica has been identified convincingly with Setaria viridis (Eda et al., 2013). The wild progenitor of Panicum miliaceum remains disputed. It is possible that the ancestral populations are extinct, or else the weedy Panicum miliaceum var. ruderale represents the remnants (uut et al., 2011). P. ruderale type grains have been found as a contaminant of millet assemblages in Yangshao/Longshan sites in central China (Fuller and Zhang, 2007; Deng et al., 2015; Song et al., 2017). Several possible centres for millet domestication have been identified in China, with sites dating from the 6th millennium BCE onward located in Northern Henan; Southern Hebei; West Shandong; Manchuria, and Gansu (Liu et al., 2009; Qin, 2012; Ren et al., 2016; Stevens and Fuller, 2017). However, the precise number of possible domestication centres is still debated among scholars, and the lack of hard evidence from many sites in those areas has made it challenging to clearly resolve the issue. 
From the samples we analysed, it seems that millet had an important role in the subsistence regime of Neolithic Yunnan, however it was secondary to rice initially. As proposed by D'Alpoim Guedes (2011), millet cultivation might have facilitated the spread of agriculture in those areas of southwest China where unsuitable conditions for rice cultivation existed. This can be expected in particular in higher elevation regions or areas with steep slope, since early rice varieties coming from the Yangtze are inferred to be adapted to wet field cultivation systems (Weisskopf et al., 2015a, Weisskopf et al., 2015b; Deng et al., 2015), in contrast to the upland rice that developed subsequently on the trajectory from Guangdong/Guangxi to Southeast Asia (Fuller et al., 2011). A mixed crop economy in Yunnan would have reduced crop failure risk, facilitating human long-term occupation of those areas at a high altitude (e.g. D'Alpoim Guedes, 2011; D'Alpoim Guedes and Butler, 2014; D'Alpoim et al., 2015). The prominence of rice cultivation at Baiyangcun might have been due to wetter climatic conditions (in comparison to Dadunzi site, a slightly later Neolithic site in northern Yunnan where presently annual precipitation is about $650 \mathrm{~mm}$; annual precipitation at Baiyangcun is instead about $750 \mathrm{~mm}$ ). Although in either case rainfall is too low to support rainfed rice (Jacquot and Courtois, 1987; Fuller et al., 2011), which would instead have had to rely on alluvial flooding or irrigation from the river. In which case, a key factor is likely to be the wider alluvial plain area near Baiyangcun, suitable for rice cultivation.

\subsection{Pulses}

Not many pulse remains were recovered and identified, but 16 seeds of soybean (Glycine cf. max/soja) were spread across 6 samples (Fig. 4G). The domestication process of the soybean has thus far been documented by evidence for seed size increase, which has been hypothesized to have occurred on multiple occasions, including in North China and Japan, and possibly Korea (Lee et al., 2011). To date the most likely loci of domestication in China has been identified in the Yellow River basin (Lee et al., 2011; Fuller et al., 2014), where seed size change marking the domestication episode is evident over the course of the Yangshao period (4th and 3rd millennium B.C.) at rates comparable to change documented in other pulse crops (Fuller et al., 2014). Early finds of soybean, that could be gathered wild, or the earliest stage of pre-domestication cultivation, come from Jiahu (7000-6600 BCE; Zhao and Zhang, 2009), Baligang (6700-6500 BCE; Deng et al., 2015), and Bancun (6000-5000 BCE; Kong et al., 1999). Charred grains of soybean have been reported only from Yinpanshang, an early Neolithic site in northern Sichuan (3300-2600 BCE; Zhao and Chen, 2011), and the finds from Baiyangcun are the earliest report of soybeans in Yunnan. Later reports of soybean both in north, central and southwest China were associated with western domesticates, such as wheat and barley. In Yunnan soybeans have been found in association with wheat at the Bronze Age site of Haimenkou (1500-1200 BCE; Xue, 2010). This has led to the hypothesis that the soybean reached Yunnan with the later spread of western domesticates such as wheat (Stevens et al., 2016; D'Alpoim Guedes et al., 2013). However, our finds from Baiyangcun suggest that 
soybeans diffused to southwest China earlier than previously thought, and most likely in association with the spread of millets and rice. Nevertheless the soybeans recovered are on the small side, comparable to Early Yangshao rather the Longshan examples from the Yellow River basin (Lee et al., 2011; Fuller et al., 2014) suggesting that this represents a form that had diffused out of central China prior to the full seed size increase associated with domestication. A few examples of a small-seeded Vigna sp. have also been found (ig. 5). These occurred as single seeds in four different contexts. They are readily identifiable by their barrel shape and visible plumule remnants on the interior of the cotyledon. Three major Vigna crops were domesticated in prehistoric India (Fuller and Harvey, 2006), while rice bean (V. umbellata) is thought to originate in mainland Southeast Asia (Castillo and Fuller, 2010; Castillo et al., 2016a, Castillo et al., 2016b), and azuki bean (Vigna angularis) in Japan and/or Korea (Lee, 2013). The present specimens do not match any of the domesticated crops and suggest a smaller-seeded Vigna taxon, yet to be identified from among several potential candidates that could have occurred wild in Yunnan (Tomooka et al., 2003). Possibly similar small Vigna seeds have been reported from Neolithic Dadunzi (Jin et al., 2014) and Bronze Age Baodun, Sichuan (D'Alpoim Guedes et al., 2013). Further work is need to unravel the role of gathering or potential cultivation of a local Vigna legume.

\subsection{Fruits and nuts}

A few seeds of edible fruit and nut species were found in the samples. Fruit species are present in very low counts throughout the sorted samples reported here. Possible collected edible wild plants include hawthorn (Crataegus sp.), represented by seeds (Fig. 4H), and what has been identified as endocarp of chinaberry (Melia azedarach), and another fruit pip provisionally referred to as cf. Garcinia sp., although this identification requires further comparative study. A few fragments of melon (Cucumis cf. melo) seeds were also found, preserved mineralized (Fig. 6A), possibly indicating that these had been ingested and excreted (see Murphy, 2014). It is possible this species was cultivated, as it was domesticated in the lower Yangtze region (Fuller et al., 2014), and was likely cultivated in the Neolithic of the middle Yangtze since ca. 4000 BCE (Nasu et al., 2012), and thus could have reached Yunnan with the spread of other cultigens. However, its low presence in the samples makes its status difficult to determine, and wild melon can be expected to have been available in the region (Yang and Walters, 1992). Nut species are better represented, accounting for $10 \%$ of the overall total identifiable remains, and were present in $45 \%$ of the sorted samples. Presently the only identifiable species is Euryale ferox (foxnut), with 60 identifiable fragments (Fig. 6B). Wild species are not very numerous and when present, have rather low counts. This might indicate that wild food gathering, although present, did not play a major role in the early subsistence at Baiyangcun. A few fragments of other likely fruits and nuts are still awaiting identification.

\subsection{Field weeds}


Several types of weed species, both of rice and millets, are consistently present, and recovered from $82 \%$ of the sorted samples (see Fig. 3), although each species is only sparsely represented. These species most probably represent part of a weed assemblage which is dominated by barnyard grass (Echinochloa sp.) (Fig. 6F), followed by Digitaria species, a common weed of rice or millets (Fig. 6C), and thirdly by green bristlegrass (Setaria viridis), a weedy form of wild foxtail millet (Fig. 6D). Echinochloaaccounts for only about 3\% of the total identifiable remains, yet is the fifth most ubiquitous species, found in $54 \%$ of the total samples sorted. Other wild grass weed species include, Setaria verticillata (ig. 6E), Eragrostis sp. and cf. Poa. Commonly found sedge weeds include Fimbristylis sp., and Schoenoplectus mucronatus (Fig. $\underline{6}$ ). Other weed species include Stachys/Mosla sp., sometimes preserved mineralized (Fig. $\underline{6}$ ).Wetland weeds are most often associated with rice remains in the samples, thus it seems likely that rice was grown in the lower lying wetland areas, and that dry upland rice varieties may have not yet developed at the time.

Echinochloa sp. is a common weed found in paddy rice agriculture. However, two species have been domesticated and are grown as cereals: Echinochloa escultenta (Japanese barnyard grass), and Echinochloa frumentacea (Indian sawa millet). The former is cultivated widely in the temperate areas of Japan, Korea and northern China, and the latter is found in more tropical areas of India, and eastward to Yunnan (De Wet et al., 1983; Chen and Phillips, 2006). Wild use of Echinochloa has been attested in the Chinese Neolithic, as recently reported by $\underline{\text { Yang et }}$ al. (2015). Phytoliths and starch remains on stone tools demonstrated how wild Echinochloa was processed as food resource at the site of Shangshan, in the Lower Yangtze region (one of the key areas for rice domestication in China) by 7000 cal B.C. (Yang et al., 2015). In the samples from Baiyangcun reported here. Echinochloa is frequently found in samples that are rich in rice, therefore we believe that at Baiyangcun Echinochloa was more likely a weed of rice cultivation, and not cultivated itself as a food resource. However, this possibility cannot be completely ruled out, and it could also have been an edible weed that contributed additional caloric value to rice harvests. More work on this taxon will be needed in future research.

Finally, a total of 97 Chenopodium sp. seeds were found (Fig. 6H), spread throughout over half of the sorted samples. This species is present in a rather low quantity in each sample, and although Chenopodium has been found as a possible cultivated species at earlier dates in other parts of China (D'Alpoim Guedes and Butler, 2014), its low count from Baiyangcun samples seems to suggest that it is more likely present in the assemblage as a weed species of millet. Nevertheless, further investigation of domestication status of Chenopodium is warranted as domesticated forms of C. album (syn. C. giganteum) are cultivated ethnographically in Yunnan and the Himalayas (Pratap and Kapoor, 1985; Zhu et al., 2003). 
Extremely well preserved mineralized remains were recovered from layer $23 \mathrm{~S} 2$ in Trench 2. In this sample apart from a few charred grains of rice and Echinochloa, all macro-remains, including other cultivated species, such as Setaria and Panicum, as well as field weeds, and fragments of Euryale and melon seeds, were mineralized. This cultural layer is the second to last before the bedrock, lying above layer 24, which produced relatively few charred plant remains. Layer 23 represents the beginning of human occupation and activities at the site, but more work needs to be done in order to better understand the context and the reason behind the mineralisation of its remains. Mineralisation of seed remains occurs when there is a high presence of calcium phosphate in the soil; in archaeological contexts this happens most often in association with faecal matter and urine. This finding from the Baiyangcun samples could therefore indicate a build-up of sewage or animal dung within this area during the initial human occupation of the site.

\subsection{Archaeobotanical sequence: evidence for agricultural change?}

Overall, the assemblage composition appears fairly homogeneous throughout all the samples; there is no substantial change in the crop package between the two major periods of occupation at Baiyangcun. Minor differences in the overall frequency of the species are present between Period 1 and Period 2/3 (see Fig. 7). Rice and millet (Setaria) ratio shows some changes between the two periods of occupation, with rice being the more prominent crop during the first period, but decreasing substantially in relation to foxtail millet in the later occupation of the site. Panicum miliaceum(broomcorn millet) is not very well represented in either of the periods, accounting for just about $1 \%$ of the total identifiable remains, and even showing a slight decrease in the later phases in samples from Trench 1. Samples from Trench 1 appear generally richer in remains during Period 2/3 compared to Period 1. Samples from Trench 2 appear richer in cultivated crops during phase 1 ; however, there is a substantial increase of sedges and other grasses in the samples from this trench during Period $2 / 3$, an increase that is also shared with samples from Trench 1 . In the later phases there is also an overall increase in the ratio of rice spikelet bases to rice grains, and the number of immature millet grains. This could indicate changes in processing habits, such as an increase in small scale processing, hence a greater prevalence of this material within the generated waste. However, at present distinguishing between rice and millet weeds is still rather difficult, and it should be a target for future research. Soybean and melon seeds are equally represented in both periods. Finally, there is a slight increase in pulses, nuts and wild species in the later levels of occupation throughout the site.

\subsection{Comparative discussion}

Only a few early sites in Yunnan have been investigated archaeobotanically, providing macrofossil evidence through the implementation of systematic flotation that allows us to

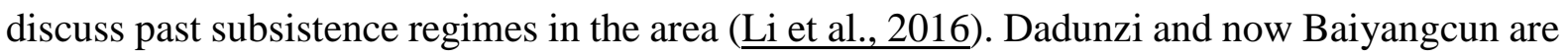


the earliest of such sites. Subsistence at Dadunzi was likely a mixture of upland dry millet and lowland wet rice cultivation, with millet being prominent (Jin et al., 2014). At Baiyangcun, subsistence was also likely based on a mixed millet and rice crop economy, however, rice seems to have had a more prominent role during the initial phase of occupation, becoming secondary to millet (Setaria italica) during the last phases. This shift is paralleled by an increasing proportion of upland versus wetland weeds (Fig. 8), which probably reflects input from millet and rice harvests, respectively. Baiyangcun is located in an area affected by the subtropical monsoon, with distinctive wet and dry seasons, but rainfall today is too low to support dry rice, i.e. $<800 \mathrm{~mm} /$ annum (Jacquot and Courtois, 1987; Fuller et al., 2011), and even under wetter conditions in the past it is likely to have been marginal. Thus a key factor is rice cultivation for the site must be its proximity to an affluent of the Jinsha River, and wide level floodplains on which wet rice could be supported by seasonal flooding and/or water management. Seasonal river floods can be expected to have provided the Baiyangcun inhabitants with a reliable and abundant water supply for paddy field rice, and at present we see no reason to hypothesize any systematic water management, although this deserves further investigation. Rice fields were probably located next to the river and in areas reached by early summer floods from both monsoon rainfall and up-river snowmelt. Millet cultivation based on rainfall would then have been located on the surrounding low slopes and areas beyond the reach of the floods. If sowing took place immediately following the floods, farmers would have been able to judge in which areas to sow millet based on the varying extent of floods. The relative increase in millet may be due to the simple fact that land area under millets could be readily expanded, whereas suitable alluvial sites for rice would have remained more or less the same over time.

Our data disprove the recent hypothesis for agricultural development of $\underline{\mathrm{Li} \text { et al. }}$ (2016). Li et al. (2016) discuss the overall agricultural development of the YunnanGuizhou plateau region, based largely on phytolith evidence and the few published archaeobotanical data, and they hypothesized that the first stage of agriculture in the area (2800-1900 cal B.C.) was based solely on rice cultivation. Our finding of millets, both Setaria italica and Panicum miliaceum, throughout the site of Baiyangcun contradicts this and indicates that millet cultivation was important from at least ca. 2600 BCE when Baiyangcun was first occupied. Millets and rice appear together also at the slightly later site of Dadunzi (2000-1600 cal B.C.). We therefore propose that millets and rice arrive together in Yunnan as part of a crop package, probably derived from Sichuan (D'Alpoim Guedes et al., 2013). Here, both crops appear cultivated together at Baodun at around $2500 \mathrm{cal}$ B.C. (D'Alpoim Guedes et al., 2013). The Sichuan early agricultural systems seem to have had two source regions: the middle Yangtze valley to the east for rice cultivation, and the north for millet cultivation. We 
suggest that the separate spread of the two economic traditions met at Baodun, and presently provide the first instance of the mixed rice and millet crop economy in southwest China. It seems possible that this mixed millet and rice economy then spread from Sichuan to Yunnan as a package, and it was then adapted to the local ecological and climatic conditions, favouring either one of the two main crops if encountering drier or wetter conditions. Preliminary analysis of Baiyangcun samples has also shown how other species were present, such as soybean. However, soybean has not been found at Baodun, or any of the other sites in Sichuan, apart from Yingpanshan. It seems that soybean arrived to Yunnan together with rice and millets, contrary to the previous proposal that soybean was a later secondary crop dispersal from the north based on their co-occurrence with the earliest wheat at Haimenkou in the mid Second Millennium BCE (Xue, 2010; Stevens et al., 2016). The reason why soybean is missing from many sites, such as in Sichuan, is unclear, and it is possible that interest in soybean related to traditions of diet and/or agriculture in which legumes were more or less favoured. This requires further investigation.

\section{Conclusion}

The agricultural transition of Yunnan seems to have taken place as early as the first half of the 3rd Millennium B.C. New archaeobotanical evidence obtained through flotation during the 2013-14 excavation seasons at Baiyangcun has shown how the early agricultural system of the region shares some similarities, as well as some contrasts with that of Sichuan, believed to be the source region for Yunnan agriculture. Contrasts with the north include the role of soybean in early agriculture and diet in Southwest China, which appears to have varied. Both rice and millets had a prominent role as major crops since the early stage of agricultural practice in Yunnan, as they had slightly earlier in Sichuan. Rice would have been cultivated in wet, flooded alluvial contexts whereas rain-fed millet cultivation took place further from the river. The presence of wetland rice cultivation in Yunnan differs from the available inferences that early rice in mainland southeast Asia was largely a dry, rain-fed crop in prehistory (Castillo and Fuller, 2010; Fuller et al., 2011, Fuller et al., 2016a, Fuller et al., 2016b; Castillo et al., 2016a, Castillo et al., 2016b). Millet cultivation at Baiyangcun included both northern Chinese domesticates, Setaria italica and Panicum miliaceum. In addition, soybeans (Glycine max), another domesticate from northern China, and melon (Cucumis melo) augmented agricultural production, and could have served in effective crop rotations with the millets. Although Yunnan has often been discussed in relation to the dispersal of agriculture from China to mainland southeast Asia, the agriculture at Baiyangcun included a diversity of agriculture not yet recorded in mainland southeast Asia, including P. miliaceum and G. max, as well as wet rice. While agricultural production was augmented by some fruits and nuts, further research is needed on the role of Yunnan in the cultivation of fruit diversity. The data reported here, 
nevertheless, highlight the great potential of systematic archaeobotany to reveal the subsistence foundations of early Yunnan and how these relate to those of other regions.

The following are the supplementary data related to this article

\section{Acknowledgements}

Excavations were conducted and funded from the Yunnan Province Institute of Cultural Relics and Archaeology. We thank Gao Yu from Peking University for her help with onsite sampling and flotation. Fieldwork and associated research by Gao and QL was supported by a grant from the National Social Science Foundation of China (Project number: 13BKG006). Travel for fieldwork (by RDM, CS, DF), aspects of laboratory analysis and AMS dating of millets was supported by the European Research Council advanced grant "Comparative Pathways to Agriculture" (no. 323842) awarded to DF. AMS dating of rice was supported by grant UOO 1113 from the Marsden Fund awarded to $\mathrm{CH}$ and TH entitled The Passage of Time. Dating the Prehistory of Southern China and Southeast Asia. Rita Dal Martello's current research is funded by an AHRC London Arts and Humanities Partnership (LAHP) Research Studentship.

\section{References}

Bellwood P (1991) The Austronesian dispersal and the origin of languages. Sci Am, 265: 8893

Bellwood P (1995) Austronesian prehistory in Southeast Asia: homeland, expansion, and transformation. In: Bellwood P, Fox JJ, Tryon D (eds) The Austronesians: historical and comparative perspectives. Department of Anthropology, Comparative Austronesian Project, Research School of Pacific and Asian Studies, Australian National University, Canberra, pp. 96-111

Bellwood P (2005) Examining the farming/language hypothesis in the East Asian Context. In: Sagaart, L, Sanchez-Mazas A, Blench R (eds) The Peopling of East Asia: Putting Together Archaeology, Linguistics, and Genetics. Routledge, London and New York, pp 17-30

Bellwood P, Dizon E (2008) Austroneasian cultural origins: out of Taiwan, via the Batanes Island, and onwards to western Polynesia. In: Sanchez-Mazas A, Blench R, Ross MD, Peiros M, Lin M (eds) Past human migrations in East Asia: matching archaeology, linguistics and genetics. London, Routledge, pp 23-39.

Bellwood P, Renfrew C (eds) (2002) Examining the farming/language dispersal hypothesis. McDonald Institute for Archaeological Research, Cambridge 
Blench R (2005) From the Mountains to the Valleys. Understanding ethnolinguistic geography in Southeast Asia. In: Sagart L, Sanchez-Mazas A, Blench R (eds) The Peopling of East Asia: Putting Together Archaeology, Linguistics, and Genetics. Routledge, London and New York, pp 31-50

Bronk Ramsey C (2009) Bayesian analysis of radiocarbon dates. Radiocarbon 51(1), 337-360 Chinese Academy of Social Sciences (CASS), Archaeology Institute Laboratory (1978) Report on the radiocarbon dating (in Chinese). Kaogu 4: 280-287

Castillo C, Fuller DQ (2010) Still too fragmentary and dependent upon chance? Advances in the study of early Southeast Asian archaeobotany. In Bellina, B, Bacus EA, Pryce O, Weissma J (eds) 50 Years of Archaeology in Southeast Asia. River Books: London, pp 93-111

Castillo CC, Bellina B, Fuller DQ (2016) Rice, beans and trade crops on the early maritime Silk Route in Southeast Asia. Antiquity 90 (353): 1255-1269

Castillo C, Tanaka K, Sato Y, Ishikawa R, Bellina B, Higham C et al (2016) Archaeogenetic study of prehistoric rice remains from Thailand and India: Evidence of early japonica in South and Southeast Asia. Archaeol Anthropol Sci 8:523-43

Chang KC (1964) Prehistoric and early historic Horizons and Traditions in South China. Curr Anthropol 5 (5): 359-375

Chen S, Phillips SM (2006) Echinochloa. In: Wu Z, Raven PH (eds) Flora of China, Vol. 22. Poaceae. Missouri Botanical Garden Press: St. Louis, pp. 515-518

D’Alpoim Guedes J (2011) Millets, Rice, Social Complexity, and the Spread of Agriculture to the Chengdu Plain and Southwest China. Rice 4 (3-4): 104-113

D’Alpoim Guedes J, Butler EE (2014) Modeling constraints on the spread of agriculture to Southwest China with thermal niche models. Quatern Int 30: 1-13

D’Alpoim Guedes J, Jiang M, He K, Wu X, Jiang Z (2013) Site of Baodun Yields Earliest Evidence for the Spread of Rice and Foxtail Millet Agriculture to South-West China. Antiquity 87 (337): 758-771D’Alpoim Guedes, J, Bocinsky KR, Butler EE (2015) Comment on “Agriculture facilitated permanent human occupation of the Tibetan Plateau after 3600 B.P.”. Science 348 (6237): 872-872 
De Wet JMJ, Prasada Rao KE, Mengesha MH, Brink DE (1983). Domestication of Sawa Millet (Echinochloa colona). Econ Bot 37 (3): 283-291

Deng Z, Qin L, Weisskopf AR, Zhang C, Fuller DQ (2015) From Early Domesticated Rice of the Middle Yangtze Basin to Millet, Rice and Wheat Agriculture: Archaeobotanical MacroRemains from Baligang, Nanyang Basin, Central China (6700-500 BC). PLOS ONE 10 (10), e139885

Eda M, Izumitani A, Ichitani K, Kawase M, Fukunaga K (2013) Geographical variation of foxtail millet, Setaria italica (L.) P. Beauv. based on rDNA PCR-RFLP. Genet Resour Crop Evol 60 (1): 265-274

Fuller DQ, Allaby R (2009) Seed Dispersal and Crop Domestication: Shattering, Germination and Seasonality in Evolution under Cultivation. In: Østergaard L (ed) Annual Plant Reviews Volume 38: Fruit Development and Seed Dispersal. Wiley-Blackwell, Oxford

Fuller DQ, Harvey EL (2006) The archaeobotany of Indian pulses: identification, processing and evidence for cultivation. Environmental Archaeol 11(2): 219-246.

Fuller DQ, Denham T, Arroyo-Kalin M, Lucas L, Stevens CJ, Qin L et al (2014) Convergent evolution and parallelism in plant domestication revealed by an expanding archaeological record. Proc Natl Acad Sci U S A 111 (17), 6147-6152

Fuller DQ, Zhang H (2007) A preliminary report of the survey archaeobotany of the upper Ying Valley (Henan Province) (in Chinese). In: School of Archaeology and Museology, Peking University and Henan Provincial Institute of Cultural Relica and Archaeology (eds) Archaeological Discovery and Research at the Wangchenggang site in Dengfeng (2002-2005). Great Elephant Publisher: Zhengzhou, pp 916-958

Fuller, D.Q, Castillo CC, Weisskopf AR (2016b) Pathways of Rice Diversification across Asia. Archaeol Int 19: 84-96

Fuller DQ, Qin L, Zheng YF, Zhao Z, Chen X, Hosoya LA et al (2009) The Domestication Process and Domestication Rate in Rice: Spikelet Bases from the Lower Yangtze. Science 323 (5921): 1607-1610

Fuller DQ, Sato Y, Castillo C, Qin L, Weisskopf AR, Kingwell-Banham EJ et (2010) Consilience of genetics and archaeobotany in the entangled history of rice. Archaeol Anthropol Sci 2(2): 115-131 
Fuller DQ, Stevens CJ, Lucas L, Murphy C, Qin L (2016a) Entanglement and Entrapment on the Pathway toward Domestication. In: Der L, Fernardini F (eds) Archaeolology of Entaglement. Left Coast Press, Walnut Creek, pp 151-172

Fuller DQ, Van Etten J, Manning K, Castillo C, Kingwell-Banham E, Weisskopf A et al (2011) The contribution of rice agriculture and livestock pastoralism to prehistoric methane levels: An archaeological assessment. The Holocene, 21(5): 743-759

Gross BL, Zhao Z (2014) Archaeological and genetic insights into the origins of domesticated rice. Proc Natl Acad Sci U S A 111(17): 6190-6197

Harvey EL, Fuller DQ (2005) Investigating crop processing using phytolith analysis: the example of rice and millets. J Archaeol Sci 32(5): 739-752.

Higham C (1996) The Bronze Age of Southeast Asia. Cambridge University Press, Cambridge Higham C (2002a) Early Cultures of Mainland Southeast Asia. River Books, Bangkok

Higham C (2002b) Languages and Farming dispersal: Austroasiatic Languages and Rice Cultivation. In Bellwood P, Renfrew C (eds) Examining the Language/ Farming Dispersal Hypothesis. McDonald Institute for Archaeological Research, Cambridge. Pp 223-232

Hunt HV, Campana MG, Lawes MC, Park YJ, Bower MA, Howe CJ, Jones MK (2011) Genetic diversity and phylogeography of broomcorn millet (Panicum miliaceum L.) across Eurasia. Mol Ecol 20(22): 4756-4771

Jacquot M, Courtois B (1987) Upland Rice. Macmillan Publishers Ltd, London and Basingstoke

Jin H et al (2014) Early Subsistence Practices at Prehistoric Dadunzi in Yuanmou,Yunnan: New Evidence for the Origins of Early Agriculture in Southwest China. In: Hein A (ed) The 'Crescent-Shaped cultural-communication Belt': Tong Enzheng's model in retrospect. Brit Archaeol Rep Int 2679. Information Press, Oxford, pp 133-140

Kong Z, Liu C, He D (1999) Plant remains unearthed from Zhuanglixi site in Tengzhou of Shangdong and their significance in environmental archaeology (in Chinese). Kaogu [Archaeology] 1999(7): 59-62

Lee GA (2013) Archaeological perspectives on the origins of azuki (Vigna angularis). The Holocene 23(3): 453-459. 
Lee G, Crawford G, Liu L, Sasaki Y, Chen X (2011) Archaeological Soybean (Glycine Max) in East Asia: Does Size Matter? PLOS ONE 6 (11): e26720

Li H, Zuo X, Kang L, Ren L, Liu F, Liu H et al (2016) Prehistoric agriculture development in the Yunnan-Guizhou Plateau, southwest China: Archaeobotanical evidence. Science China Earth Sciences 59 (8):1562-1573

Li X, Walker D (1986) The Plant Geography of Yunnan Province, Southwest China. J Biogeogr 13 (5): 367-397

Liu H, Cui Y, Zuo X, Li H, Wang J, Zhang D et al (2016) Human settlements and plant utilization since the late prehistoric period in the Nujiang River valley, Southeast Tibetan Plateau. Archaeol Research in Asia 5: 63-71

Liu X, Hunt HV, Jones MK (2009) River valleys and foothills: changing archaeological perceptions of North China's earliest farms. Antiquity 83(319): 82-95

Murphy C (2014) Mineralization of Macrobotanical Remains. In: Smith C (ed) Encyclopedia of Global Archaeology. Springer, New York, pp. 4948-4952.

Nanjing Museum (2016) Shunshanji (in Chinese). Science Press, Beijing

Nasu H, Gu HB, Momohara A, Yasuda Y (2012) Land-use change for rice and foxtail millet cultivation in the Chengtoushan site, central China, reconstructed from weed seed assemblages. Archaeol Anthropol Sci 4(1): 1-14

Pratap T, Kapoor P (1985) The Himalayan grain chenopods. I. Distribution and ethnobotany. Agriculture Ecosystems Environ 14(3-4): 185-199

Qin L (2012) Archaeobotany in the research of Agriculture in China, current status and future prospects (in Chinese). In: School of Archaeology and Museology of Peking University, Center for the study of Chinese Archaeology, Peking Universiry (eds) A collections of studies on Archaeology IX. Peking University School of Archaeology and Museology. Cultural Relics Press, Beijing, pp. 260-315

Reimer, P.J., Bard, E., Bayliss, A., Beck, J.W., Blackwell, P.G., Bronk Ramsey, C., Grootes, P.M., Guilderson, T.P., Haflidason, H., Hajdas, I., Hatté, C., Heaton, T.J., Hoffmann, D.L., Hogg, A.G., Hughen, K.A., Kaiser, K.F., Kromer, B., Manning, S.W., Mu Niu, Reimer, R.W., Richards, D.A., Scott, E.M., Southon, J.R., Staff, R.A., Turney, C.S.M. and van der Plicht., J. 
2013. IntCal13 and Marine13 Radiocarbon Age Calibration Curves 0-50,000 Years cal BP. Radiocarbon 55(4): 1869-1887

Ren X, Lemoine X, Mo D, Kidder T, Guo Y, Qin Z, Liu XY (2016) Foothills and intermountain basins: Does China's Fertile Arc have 'Hilly Flanks’?. Quaternary International 426: 86-96

Rispoli F (2007) The Incised and Impressed pottery style of Mainland Southeast Asia: Following the paths of Neolithization. East and West 57 (1/4): 235-304

Sagart L (2005) Sino-Tibetan-Austronesian: an updated and improved argument. In: Sagart L, Blench R, Sanchez-Mazas A (eds) The peopling of East Asia: putting together archaeology, linguistics and genetics. New York, Routledge, pp 161-176

Silva F, Stevens CJ, Weisskopf A, Castillo C, Qin L, Bevan A et al (2015) Modeling the Geographical Origin of Rice Cultivation in Asia Using the Rice Archaeological Database. PlosONE 10 (9): e0137024

Song J, Zhao Z, Fuller DQ (2012) The archaeobotanical significance of immature millet grains: an experimental case study of Chinese millet crop processing. Veg Hist Archaeobot 22(2): $141-152$

Song J, Wang L, Fuller DQ (2017) A regional case in the development of agriculture and cropprocessing in northern China from the Neolithic to Bronze Age: archaeobotanical evidence from the Sushui River survey, Shanxi Province. Archaeol Anthropol Sci DOI 10.1007/s12520017-0551-0

Stevens CJ, Fuller DQ (2017) The Spread of Agriculture in Eastern Asia: archaeological bases for hypothetical farmer/ language dispersal. Language Dynamics and Change 7: 152-158

Stevens CJ, Murphy C, Roberts R, Lucas L, Silva F, Fuller DQ (2016) Between China and South Asia: A Middle Asian corridor of crop dispersal and agricultural innovation in the Bronze Age. The Holocene 26(10): 1541-1555

Tomooka N, Vaughan DA, Moss H, Mixted N. 2003. The Asian Vigna: genus Vigna subgenus Ceratotropis genetic resources. Kluwer, New York.

Van Driem G (2005) Tibeto-Burman vs. Indo-Chinese: Implications for population geneticists, archaeologists and prehistorians. In: Sagaart L, Sanchez-Mazas A, Blench R (eds) The Peopling of East Asia: Putting Together Archaeology, Linguistics, and Genetics. Routledge, London and New York, pp 81-106 
Weber S et al (2010) Rice or millets: early farming strategies in prehistoric central Thailand. Archaeol Anthropol Sciences 2(2): 79-88

Weisskopf A, Lee GA (2016) Phytolith identification criteria for foxtail and broomcorn millets: a new approach to calculating crop ratios. Archaeol Anthropol Sci 8(1): 29-42.

Weisskopf A, Deng Z, Qin L, Fuller DQ (2015a) The interplay of millets and rice in Neolithic central China: Integrating phytoliths into the archaeobotany of Baligang. Archaeol Research in Asia 4: 36-45

Weisskopf A, Qin L, Ding J, Ding P, Sun G, Fuller DQ (2015b) Phytoliths and rice: from wet to dry and back again in the Neolithic Lower Yangtze. Antiquity 89(347): 1051-1063

Wu Z, Raven PH, Hong D, eds (2013) Flora of China, Volume 1. Missouri Botanical Garden Press: St. Louis

Xiao M (2001) Brief review of the Archaeology of Yunnan (in Chinese). Archaeology 12: 1063-1075

Xue Y (2010) Study of Plant Remains from Haimenkou Site in Jianchuan County, Yunnan Province (in Chinese). Dissertation, Peking University

Yang X, Fuller DQ, Huan X, Perry L, Li Q, Zhao L et al (2015) Barnyard grasses were processed with rice around 10000 years ago. Scientific Reports 5: 16251

Yang SL, Walters TW (1992) Ethnobotany and the Economic Role of the Cucurbitaceae of China. Econ Bot 46(4): 349-367

Yang, X, Wang W, Zhuang Y, Li Z, Ma Z, Ma Y, Cui Y, Wei J \& Fuller DQ, (2017) New radiocarbon evidence on early rice consumption and farming in South China. The Holocene 27(7): 1045-51

Yao A (2010) Recent Development in the Archaeology of Southwestern China (in Chinese). J Archaeol Research 18 (3): 203-239

Yunnan Provincial Institute of Cultural Relics and Archaeology et al (2003) Excavation of the Caiyunazi and Mopandi sites in Yongren Yunnan in 2001 (in Chinese). Acta Archaeol Sinica 2: $263-296$ 
Yunnan Provincial Institute of Cultural Relics and Archaeology, Dali County Cultural Relics and Yongping Cultural Relics, eds (2002) Excavation of the Xinguang site in Yongping (in Chinese). Acta Archaeol Sinica 2: 203-234

Yunnan Provincial Museum, ed (1981) The Baiyangcun site, in Binchuan County, Yunnan (in Chinese). Acta Archaeol Sinica 3: 349-368

Zhang C, Hung H (2008) The Neolithic of Southern China: Origin, Development and Dispersal. Asian Perspectives 47 (2): 299-329

Zhang C, Hung H (2010) The emergence of Agriculture in Southern China. Antiquity 84 (323): $11-25$

Zhao Z, Chen J (2011) Results of the Flotation Carried out at the Site of Yingpanshan in Maoxian County, Sichuan (in Chinese). Southern Cultural Relics 2011(3):60-67

Zhao Z (2010) Report on the archaeobotanical analysis of Shifodong site (in Chinese). In: Yunnan provincial institute of cultural relics and archaeology et al (eds) Shifodong in Gengma. Cultural relics press, Beijing, pp 368-373

Zhao Z, Zhang J (2009) Report on the analysis of the 2001 flotation of the Jiahu site (in Chinese). Archaeology 8: 84-93

Zhu G, Mosyakin SL, Clemants SE (2003) Chenopodiaceae. In: Wu Z, Raven PH, Hong D, eds (2013) Flora of China, Volume 1. Missouri Botanical Garden Press: St. Louis, pp. 351-414 


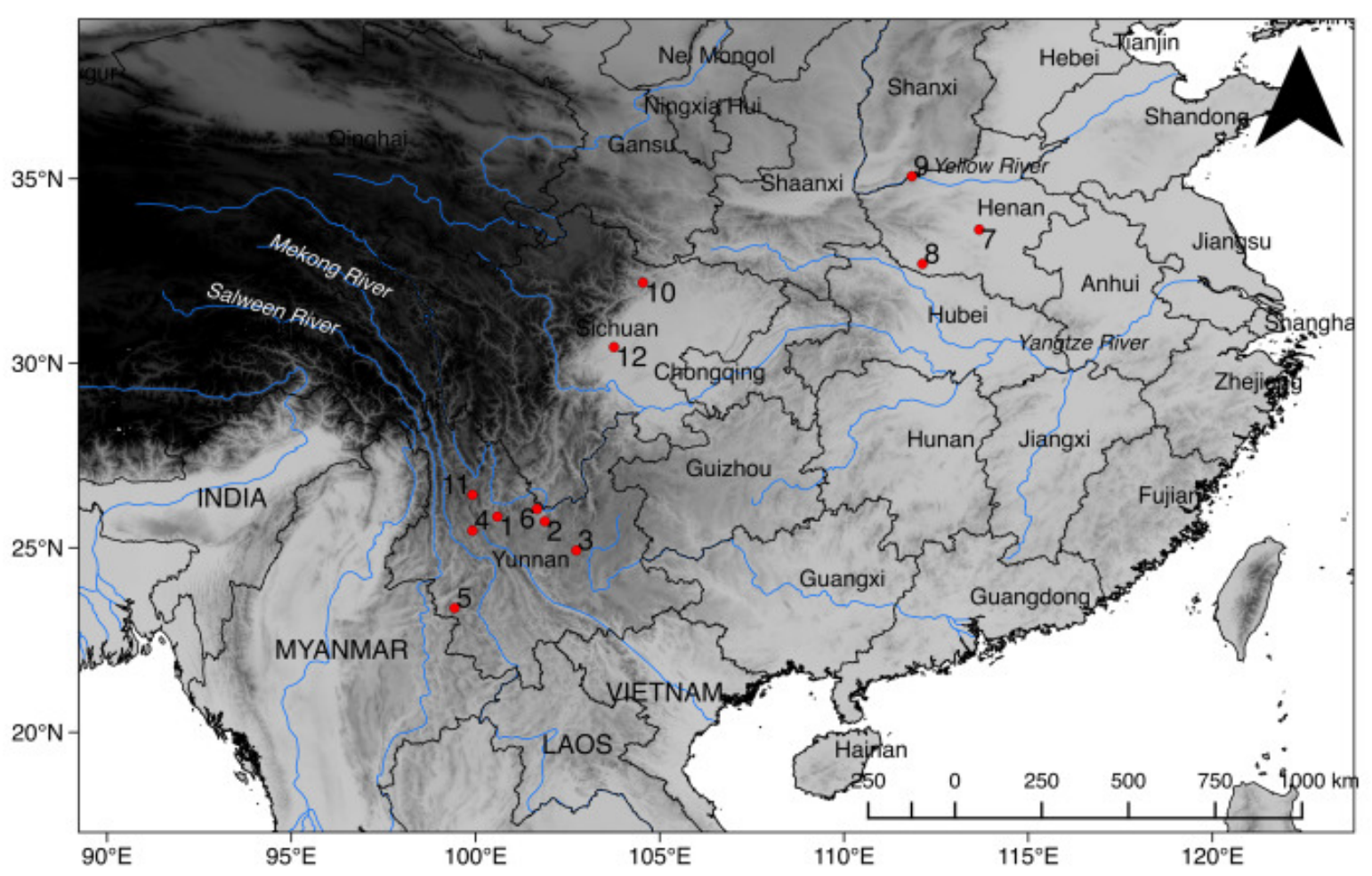

Map created using QGIS Development Team. QGIS 2.14.10- Essen 2016. QGIS Geographic Information System. Open Source Geospatial Foundation Project. http://www.qgis.org' Fig. 1. Location of sites mentioned in text: 1. Baiyangcun; 2. Dadunzi; 3. Haidong; 4.

Xinguang; 5. Shifodong; 6. Mopandi; 7. Jiahu; 8. Baligang; 9. Bancun; 10. Yingpanshan; 11. Haimenkou; 12. Baodun. Made with QGis. 


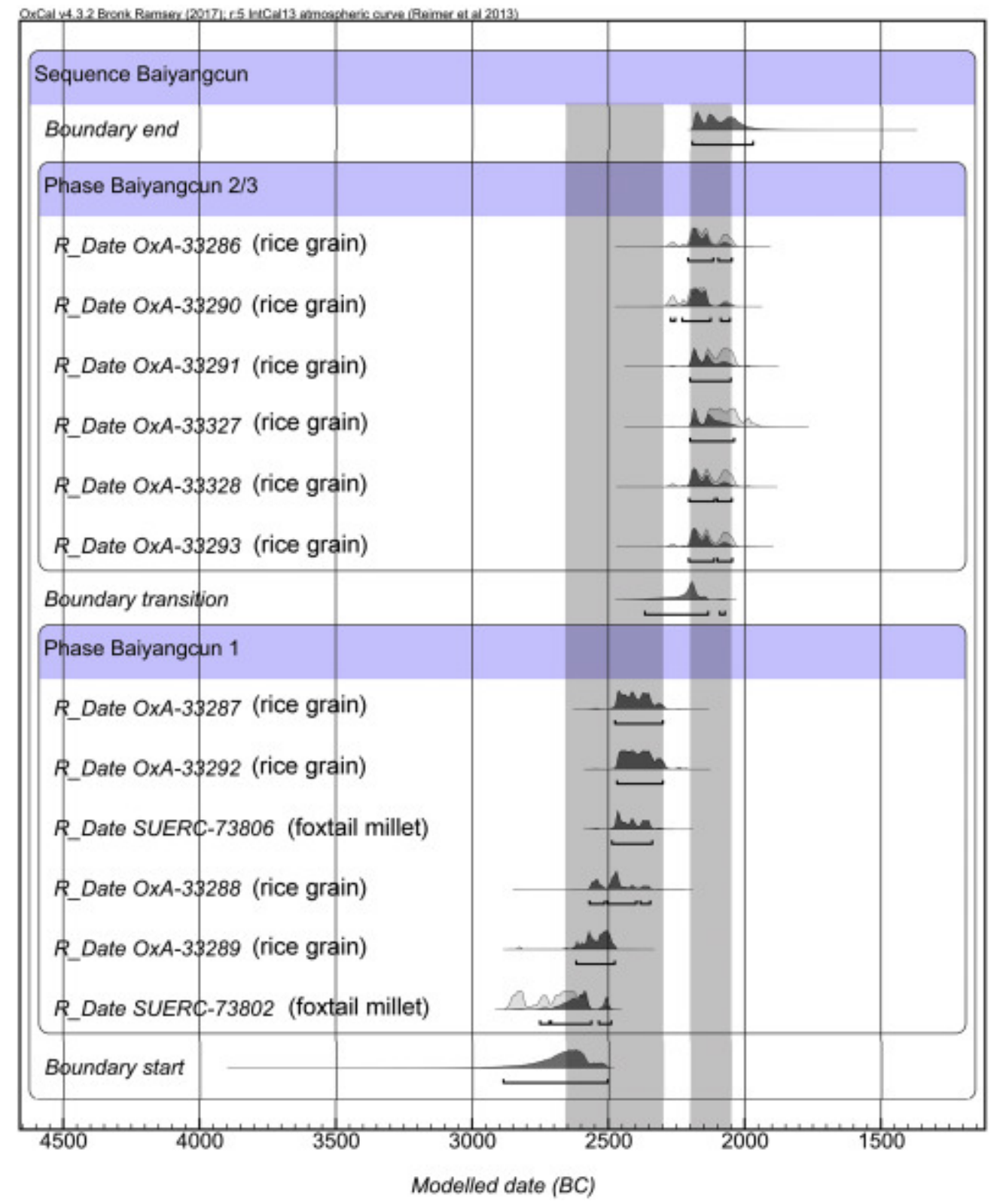

Fig. 2. Radiocarbon dates from Baiyangcun, 2013 excavation calibrated in a Bayesian model incorporating stratigraphy and phasing (Bronk Ramsey, 2009), using OxCal 4.3 software (Bronk Ramsey, 2009). See text for details. CQL code is in the Supplementary information. 


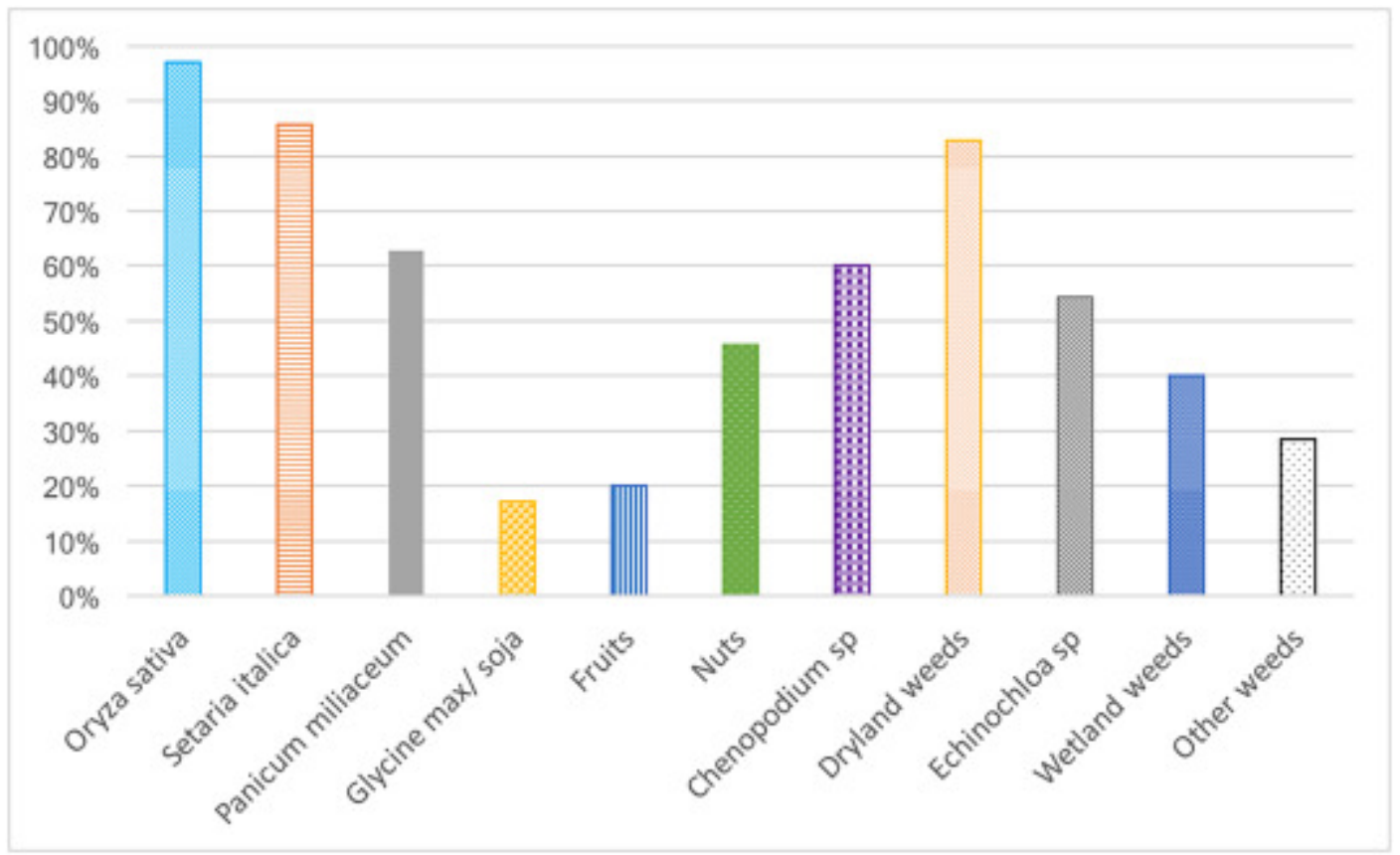

Fig. 3. Ubiquity of selected taxa across all periods of Baiyangcun based on data reported in the present paper.

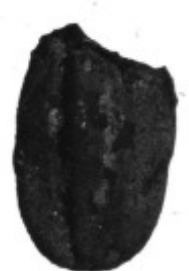

A

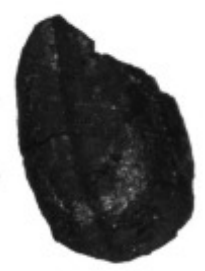

$2.00 \mathrm{~mm}$

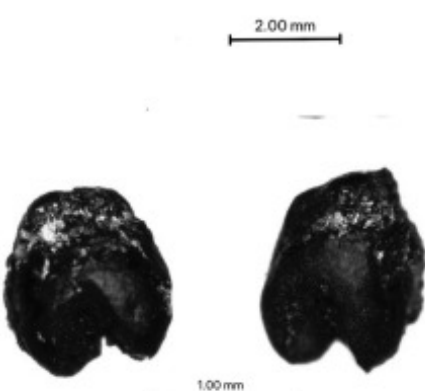

C

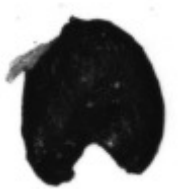

E

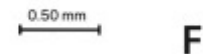

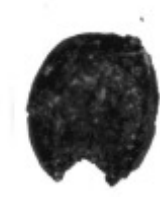

$\mathbf{F}$
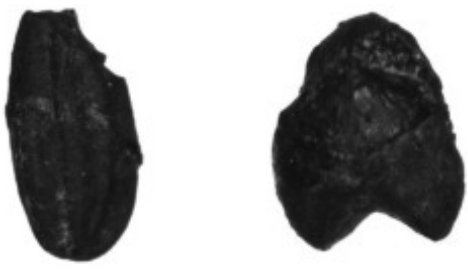

B

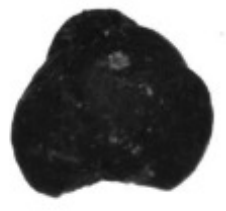

$1.00 \mathrm{~mm}$
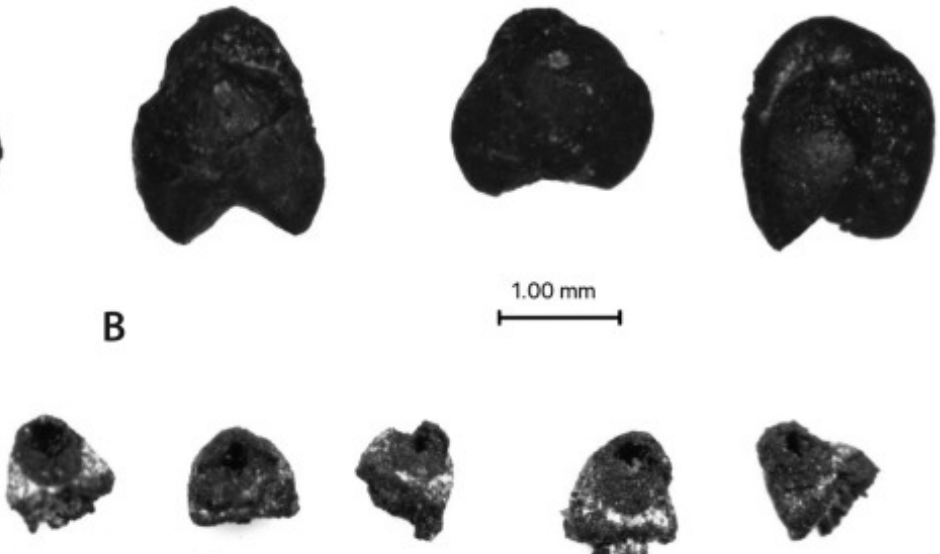

D
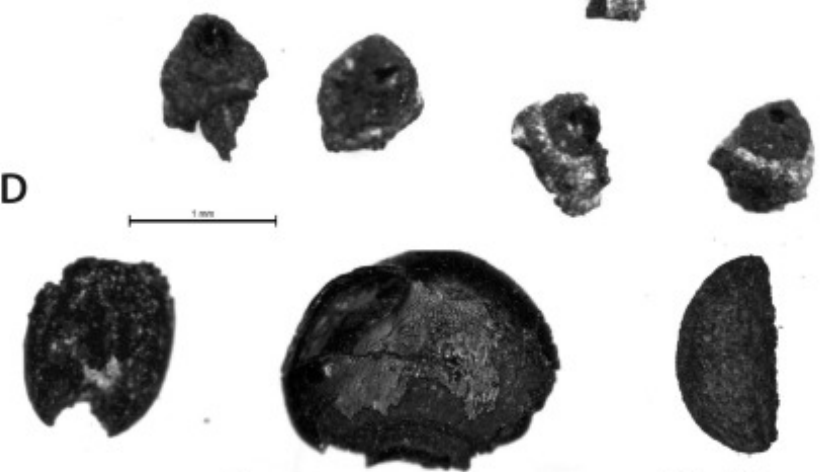

G

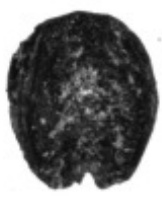

$.0 .00 \mathrm{~mm}$

Fig. 4. Photomicrographs of representative macro-remains from Baiyangcun: A. rice grain (Oryza sativa) from Trench 2/Layer 20; B. broomcorn millet (Panicum miliaceum) from Trench 2/Layer 20; C. foxtail millet (Setaria italica) from Trench 2/Layer 20; D. rice spikelet bases of domesticated type (Oryza sativa) from House F7; E. immature foxtail millet grain 
(Setaria italica) from pit H118; F. barnyard millet/grass grains (Echinochloa sp.) from Trench 1/Layer 10; G. Soybean (Glycine cf. max/soja) from pit H47; H. hawthorn (Crataegus sp.) from Trench 2/Layer 21.

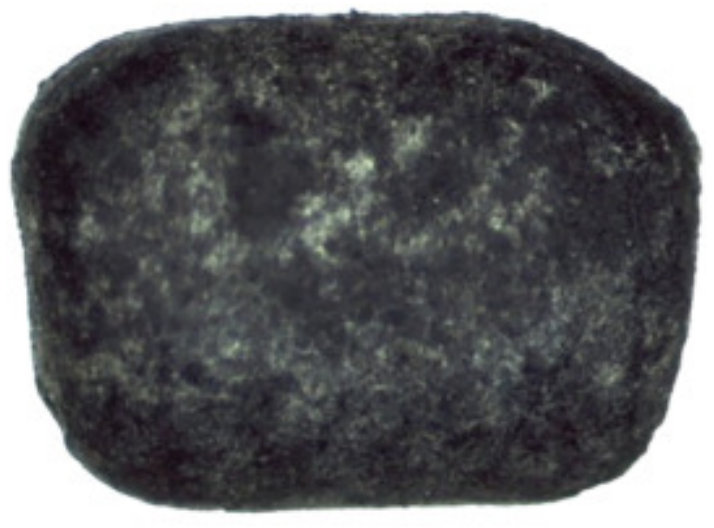

$1.00 \mathrm{~mm}$

Fig. 5. Photomicrograph of Vigna sp. cotyledon (exterior view) from Trench 1/Layer 10.

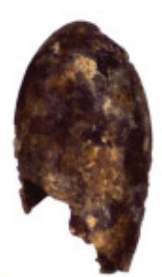

A
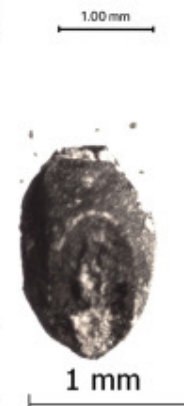



B

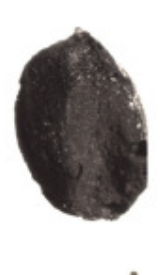

F

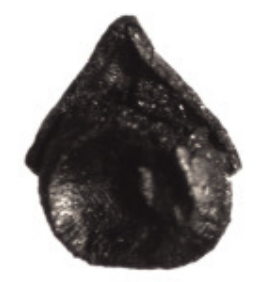

$0.5 \mathrm{~mm}$

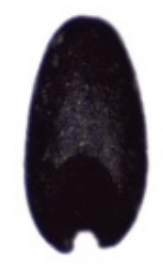

C
$0.50 \mathrm{~mm}$

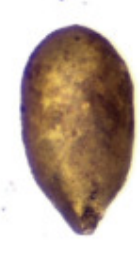

$\mathrm{G} \stackrel{0.50 \mathrm{~mm}}{\longmapsto}$

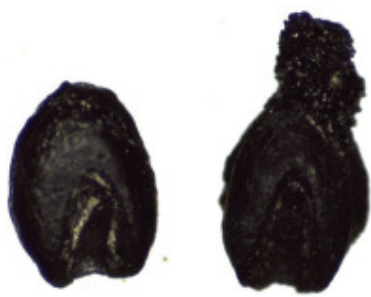

D $\stackrel{0.50 \mathrm{~mm},}{\longleftarrow}$

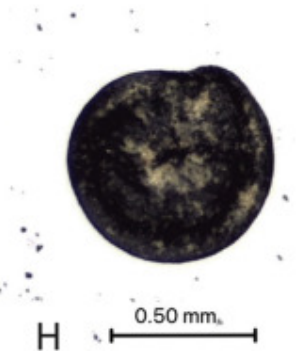

Fig. 6. Photomicrographs of selected specimens: A. mineralized melon (Cucumis cf. melo) seed from Trench 2/Layer 23; B. Fragment of charred foxnut (Euryale ferox) from Trench 2/Layer 6; C. caryopsis of crabgrass (Digitaria sp.) from Trench 2/Layer 6; D. Caryopses of green foxtail (Setaria viridis) from pit H118; E. Caryopsis of wild/bristley foxtail (Setaria cf. verticillata) from Trench 1/Layer 13; F. Nutlet of ricefield bulrush (Schoenoplectus mucronatus) from Trench 2/Layer 3; G. Mineralized seed of wild mint 
(Stachys/Mosla sp.) from Trench 2/Layer 23; H. Charred seed of goosefoot (Chenopodium sp.), from Trench 1/Layer 10.

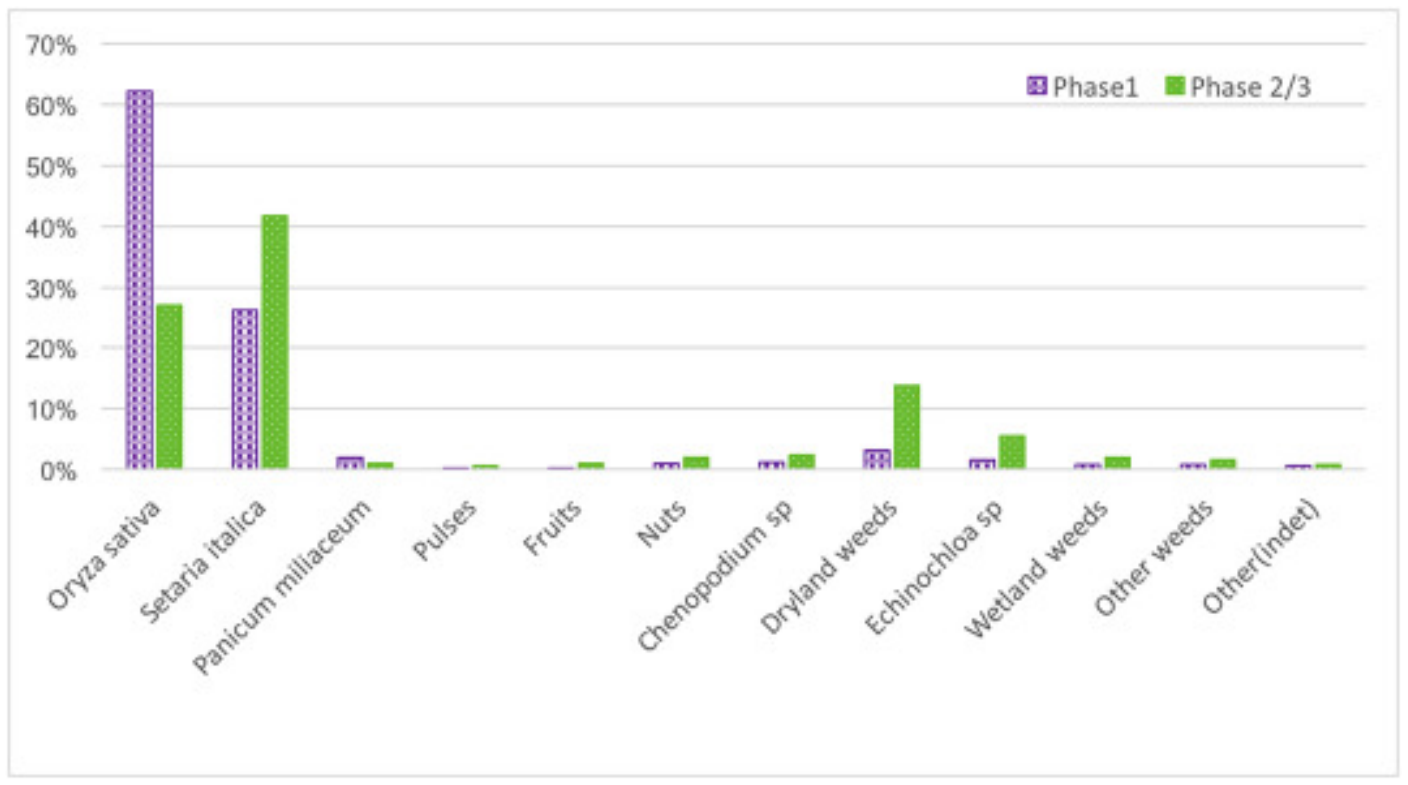

Fig. 7. Relative frequency of major crop and weed categories comparing Period 1 and combined Periods 2 and 3.


Fig. 8. Pie charts comparing the relative proportions of Echinochloa, dry/upland weeds and wetland rice weeds in Period 1 and combined Periods 2 and 3. 


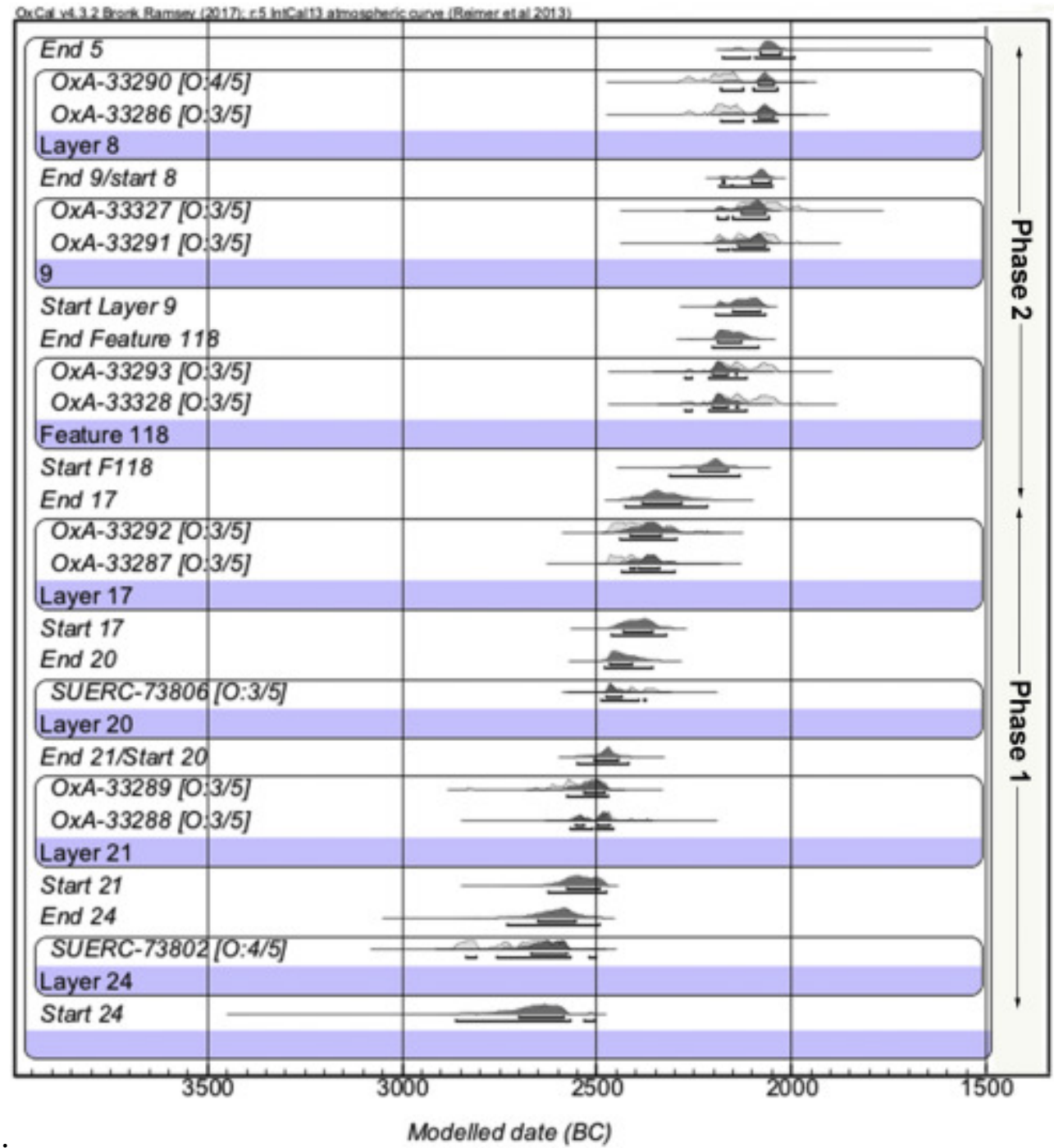

Fig. S1. Radiocarbon dates from Baiyangcun, 2013 excavation calibrated in a Bayesian model incorporating stratigraphy and phasing (Bronk Ramsey, 2009), using OxCal 4.3.2 software. 